\title{
Re-Creating Awareness of Traditional Leafy Vegetables in Communities
}

By

Voster Ineke H.J. ${ }^{* 1}$ Jansen van Rensburg Willem, ${ }^{1}$, Van Zijl J.J.B. ${ }^{1}$ and L. Venter Sonja ${ }^{1}$

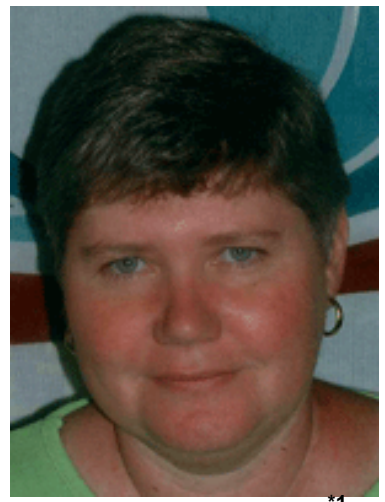

Vorster H.J. Ineke
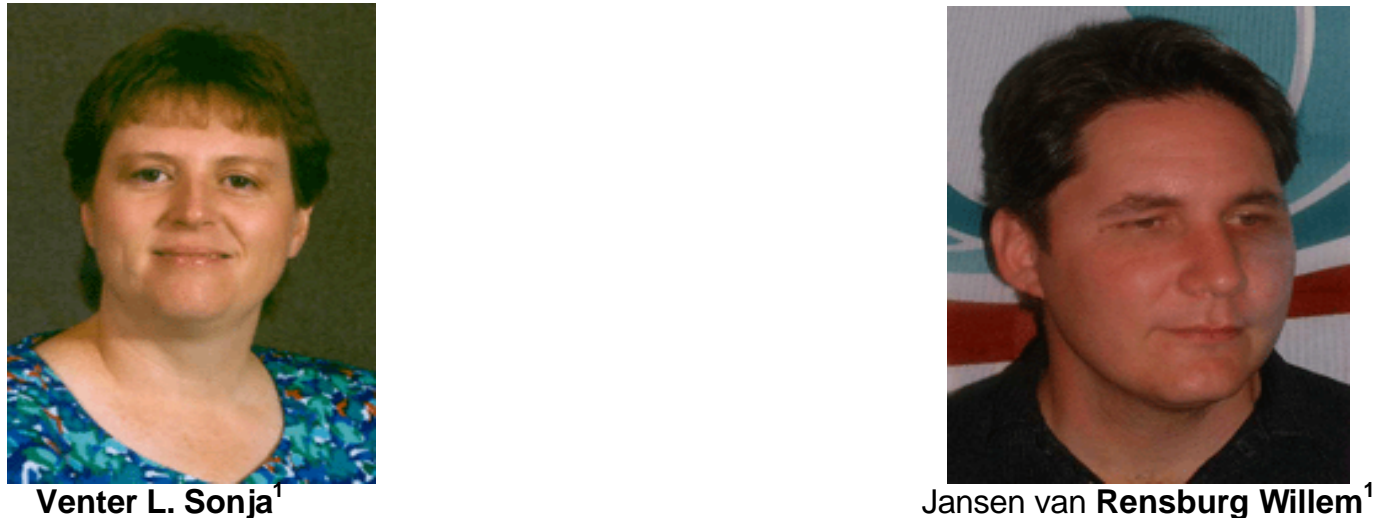

*Corresponding author Email: $\underline{\text { ivorster@arc.agric.za }}$

${ }^{1}$ ARC-Roodeplaat Vegetable and Ornamental Plant Institute,Private Bag x293,Pretoria,0001 ,South Africa.Tel: + 27128419611 


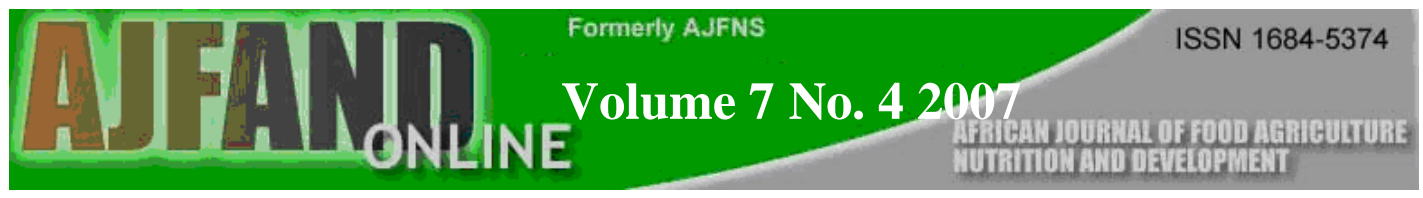

\begin{abstract}
Research and extension in South Africa has been labelling traditional leafy vegetables as weeds since the 1960s when they started encouraging households to produce food seen in the shops. This negative perception has led to an unwillingness to use and conserve these 'poverty foods', as many community members have labelled them. The status of these crops needed to be improved to help people realise the importance of these crops in their daily diet. Awareness activities in six communities made use of production training sessions in seven schools and eight community gardens, discussion groups, garden competitions, cooking competitions, recipe collection, awareness days, local resource collection activities, participatory selection and a radio talk. Discussions about use and conservation status of these crops during the data collection phase stimulated discussions on various aspects of these crops and caused an increased awareness about the poor conservation status within the communities, leading to the appointment of keepers of specific seed. The local resource collection efforts and gene bank actions caused community members to appreciate their natural resources more and emphasised the vulnerability of the crops, and their important role in keeping the biodiversity available for them and for future generations. In an effort to create awareness of the traditional plants at all levels within the community, schools (where possible) and community gardens were targeted during the training and awareness campaigns. The awareness campaigns culminated in a school garden and community garden competition, as well as a cooking competition. Participatory selection was used to expose the community members to new crops and to variations in the crops that they know. Community evaluation of these crops created a better understanding for researchers and community members, leading to improved cooperation. A noticeable increase in demand for seed and training on production methods was the result of the awareness activities within the communities.
\end{abstract}

Keywords: Leafy vegetables, Awareness, Biodiversity, Use 


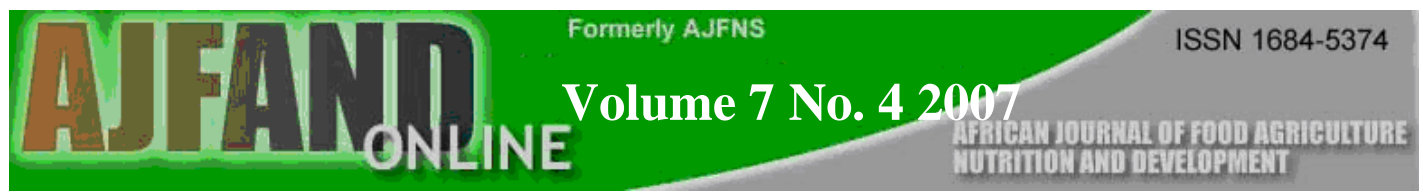

\section{INTRODUCTION}

In South Africa local people formerly ate a diet of meat, milk, wild cereals and wild plants, but the Pedi proverb "Meat is a visitor, but morogo a daily food" (morogo are traditional leafy vegetables) has become a reality for most [1]. The use of traditional leafy vegetables in rural communities has reached a low point, as many have labeled their dishes as 'poverty food'. This unfortunate label has stigmatized these healthy crops with, especially, the youth. The women are the custodians of this crop, as they are responsible for all aspects of these crops. The constant reminders from both research and extension from the 1960s to the present day to remove the 'weeds' (usually African leafy vegetables) from their crops has attached a 'backward knowledge' label to the 'poverty food' label. Parents have found it difficult to motivate their children to learn something about their traditional food crops and the effect of these labels are apparent in the youth; they hardly know the plants and prefer to eat the more fatty western foods. Studies done on foods harvested from the wild in South Africa from the 1930s to the 1980s culminated in a book where the authors raised their concern about the loss of indigenous knowledge associated with these foods [1]. Addressing the problem of the poor image is the key to the survival of these crops in rural communities. This study looks at the problems encountered and how they were addressed to help improve the image of these crops.

\section{METHODOLOGY}

The work was done from 2000/1 to 2003/4 in three villages in South Africa that differ in terms of ethnicity, geography and climate. Diversity between the villages ensured as wide a range as possible in terms of uses and status of the traditional vegetables, thus being more representative of the diversity found within the country. The villages each represented a geographical area and an ethnic grouping. The villages were:

- Watershed, Ladysmith, KwaZulu-Natal: predominantly Zulu, close to the foothills of the Drakensberg with semi-arid conditions, summer rainfall, hot summers and bitterly cold winters (snows occasionally). Watershed's closest large town is about 45 minutes by taxi. There is no direct taxi service.

- Bushbuckridge, Limpopo Province: predominantly Shangaan, but five cultural groups are present. High summer rainfall, sub-tropical, mild winters, close to the Kruger National Park. Bushbuckridge is peri-urban, with a supermarket within the community.

- Mars and Glenroy, near Polokwane, Limpopo Province: two neighbouring villages with predominantly Pedi people, semi-arid with hot summers, cold winters, low summer rainfall, mainly savannah type landscape. Mars and Glenroy's closest large town about one hour away, no direct taxi service.

Information of the crops, their uses, importance and conservation status within communities were mainly done by using participatory approaches [2, 3]. Due to time constraints, much of the data collection was done in a rapid and extractive way, with participation increasing as the project progressed and the community trust grew.

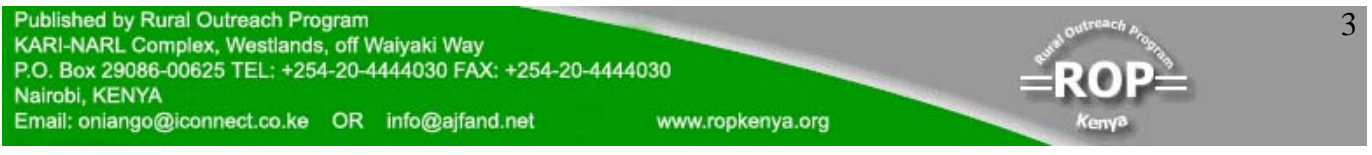




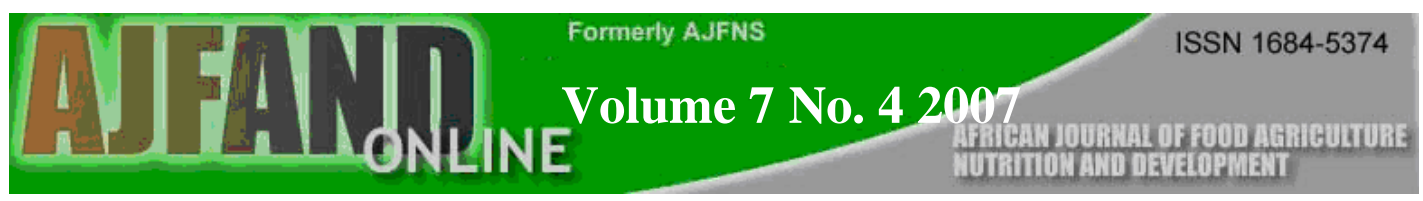

The information from these studies showed the need to increase awareness of these plants due to the loss of status within South Africa [4]. Techniques used to increase the status of these plants within communities included interviews, group discussions, local resource collection, garden competitions, cooking competitions, training sessions, awareness days and participatory selection.

Local resource collection was used to identify the plants and lead to the discussion about the preparation, preservation methods, seed systems, cultivation, popularity, recipes and status of these crops.

The cooking competition was left in the hands of the community and was held on the awareness day hosted by the community. The judging was based on two criteria: taste of the individual dishes and variety of different recipes for the traditional leafy vegetables. The only imposed rule was that the tasting panel had to consist of school children and adults from both gender groups. This was added to ensure that feedback from young and old, male and female was available to the ladies during the evaluation.

Seed systems were discussed and evaluated in a focus group. Women were encouraged to show their storage systems, discuss problems and give a general overview of seed systems in the community and at home.

The training of a researcher from ARC-Roodeplaat at AVRDC led to the compilation of a small manual that was handed out during training to community members and extension. Included were cultivation practices, seed harvesting tips and some alternative methods for pest control. The booklet was well received and improved upon as suggestions from the users were incorporated.

ARC-Roodeplaat trained community members and extension personnel in the gardens with some theoretical work followed by the practical planting and maintenance of the crops. The gardens were finally evaluated during the community garden competition. School children were trained, both in theory and practically, in one school garden, from which they then had to plant their own garden. Continual visits to the gardens were done to evaluate, give suggestions and answer questions. This helped us to identify problems and evaluate the effectiveness of the training and the booklet.

Garden competitions were held for community gardens and school gardens. The steps of a biodiversity fair, as described by Rijal, Rana, Subedi and Sthapit [5], were used as guidelines. School gardens were only included in Arthurstone, due to the strong extension support in the area. During the first year four schools took part, with three other schools in two communities joining these schools in the second year. Evaluation criteria for community and school gardens included the diversity of leafy vegetables grown, effectiveness of harvesting, spacing, general appearance of the garden, correct use of production guidelines and knowledge about the plants. 


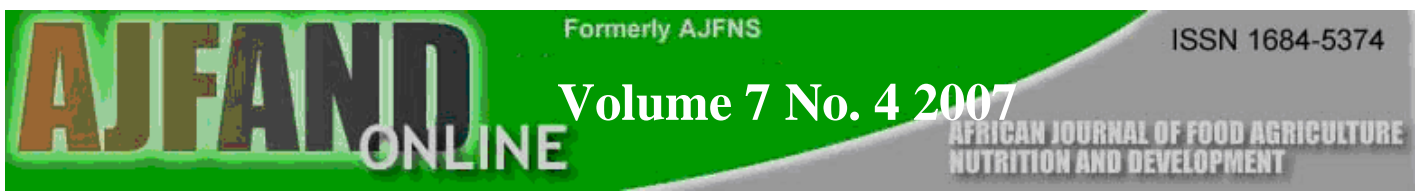

An evaluation panel consisting of teachers, extension personnel and a researcher was established, and one day was used to evaluate and determine the winners. Not only the garden, but also knowledge of the plants and its uses were included in the evaluation. Inclusion of the knowledge testing ensured that children were exposed to the holistic nature of the crop, and not just its cultivation.

During a participatory selection process [6] local and AVRDC lines were planted to ensure that farmers could compare the lines effectively. The crops were planted in single rows, and community members were asked to evaluate the lines of each crop according to their own criteria. Feedback about the lines was given at each visit.

\section{RESULTS}

\section{Preparation}

Local resource collection helped the researchers to identify the plants, know their local names as well as their importance to the ladies in the community. As the women went out collecting plants, enthusiasm grew leading to others joining the activities. The levels of excitement grew as they realized that researchers were serious about learning about these crops, thus stimulating them to share even more. The women confided later that the interest shown by researchers (and later extension) in these crops helped them to start thinking about these crops again as a resource they needed to look after. The older women realized how little the younger generation knew, and also realized that some of the crops were actually becoming scarce. They were worried about the tendency of the children to ignore the importance of the crops, and their unwillingness to consume them. The women tended to mostly use one method of preparation, with some women telling us that they would cook the same way for weeks, as long as there was fresh material available.

\section{Recipes and cooking competition}

Fifteen different recipes were collected from all the communities we worked in. Most of the foods are cooked for a short time on a very high heat, but currently the influence of this on the nutritional value is not known. This preparation method makes the best use of the local fuel wood resources, thus making them difficult to change. Feedback from the results of the cooking competition, as well as the open tasting sessions afterwards led to recipes being popular with the evaluators, being exchanged on the awareness day.

\section{Existing seed systems}

Discussions were held with the women about the conservation status of these crops in their community. The role of seed custodian, usually assigned to an old woman of high status, has been lost due to various social and economic reasons. Generally seed systems were informal, unorganized and seed exchange between family and neighbors happened regularly. Most of the seeds were stored in plastic or glass containers, with 


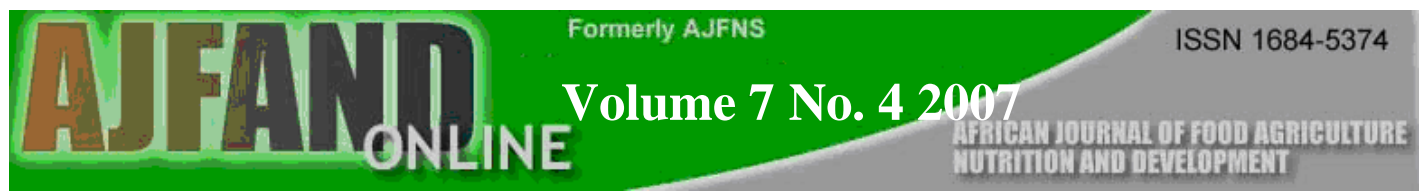

some adding ash and some not. Damage to seed led to the informal exchange of seed within the community.

Many women had not consciously realized that some of the crops were becoming scarce. One species Cucumis melo or phara has been brought close to near local extinction by livestock browsing. In one community they realized with a shock that only one person had seeds left from a specific climber that they enjoyed. The plants from these seeds were destroyed during the following season, leading to the loss of this plant within these communities. Efforts to re-introduce the species into the community resulted in a decision by the women to collect all the seeds they could in the coming season, and distribute them to a few women, to ensure the spread of risks. The community women immediately appointed two women in each community to look after phara and ensure its survival in the community [7]. How close these two accessions were will now never be known.

The National Plant Genetic Resource Center in South Africa did a seed collection trip together with the ARC-Roodeplaat within the communities at a time specified by the women as the best time to collect seed. These crops were never incorporated into their collections, but the trip helped them to realize the importance of these plants in the communities. Women were very willing to share their seed when they understood the concept of gene banks.

\section{Cultivation}

Cultivation of traditional leafy vegetables characteristically entails broadcasting of some seeds between the maize. In some areas cowpeas (edible leaves and pods) and/or cassava (edible leaves and roots) are cultivated, as they have been for generations.

The women of the community were asked if they would be interested in cultivating some of the crops, and if they were interested in possible new crops that might be of interest to them. The interest was tentative, but they decided to try it and see what the impact might be. Later evaluation of these plant brought mixed results, as some of the new plants (amaranth from AVRDC) where popular while the introduction of jute mallow (Corchorus spp.) led to non-adoption in areas where it was not known, as the mucilaginous consistency was not popular. Discussions with them helped in making choices in terms of which plants to introduce.

\section{Production training}

Cultivation of leafy vegetables had varying results in the different areas. Where the larger leaved amaranth was introduced, it is still being cultivated or broadcast, due to its high leaf yield and good taste. The cowpeas and pumpkins are also being cultivated. More broadcasting of jute mallow and spider plant (Cleome gynandra) is taking place than before. 


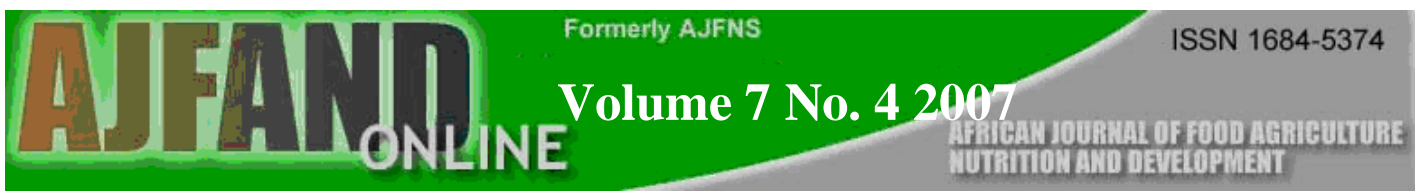

The enthusiasm of the school children was high during training, but the effectiveness of the training and the school gardens were determined by the enthusiasm of the teachers involved. The competition was well received by community and schools, and led to much community enthusiasm.

\section{Participatory selection}

During the participatory selection trials the women were asked to evaluate the crops according to their own criteria. In the first year the women identified taste as their only criteria, but as the season progressed this changed. Characteristics that became important included yield, space needed, taste and how much labour was needed. Where space was limited, bushy types were preferred to spreading types, larger leaves were generally preferred to smaller leaves (if the taste was acceptable), and minimal labour needs were preferred. Feedback about the crops was given at each visit.

\section{Awareness days}

The season in the communities ended with awareness days. The rules and program were determined by the community, thus ensuring their buy-in. The awareness competition events, held at school and community gardens, culminated with the handing out of prizes. Likewise the cooking competition took place on this awareness day, with children and adults taking part in the evaluation of the dishes. Schools were asked to provide entertainment with a message about African leafy vegetables where possible. One school performed a play where the message of health and leafy vegetables was transferred in a hilarious way. In Watershed a local radio station interviewed the women and further disseminated the message about the value of traditional leafy vegetables to a large area in the province.

\section{General awareness activities}

To help spread the message of the importance of African leafy vegetables, a logo and slogan was designed that was incorporated into all the activities and publications where possible. T-shirts were printed that were worn regularly during community work was done. T-shirts were handed to children participating in the school gardens, to influential people in the community, women involved with the project and extension personnel involved in the project. The t-shirts were worn with pride and became a uniform on special days with the project.

\section{DISCUSSION}

The tendency of the women to use mainly one method of preparation, as well as preparing the dish daily for weeks on end, led to the suspicion that the 'poverty food' label might be boosted by the monotonous way in which the food was prepared. To help address this, the women should benefit from training in different traditional vegetable recipes without fear of being criticized. The cooking competition was incorporated into the awareness day to help with this process. The fifteen recipes

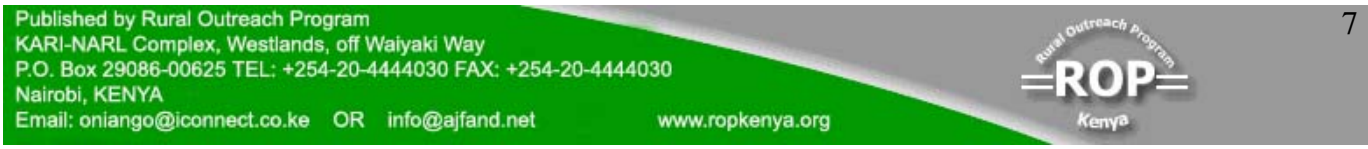




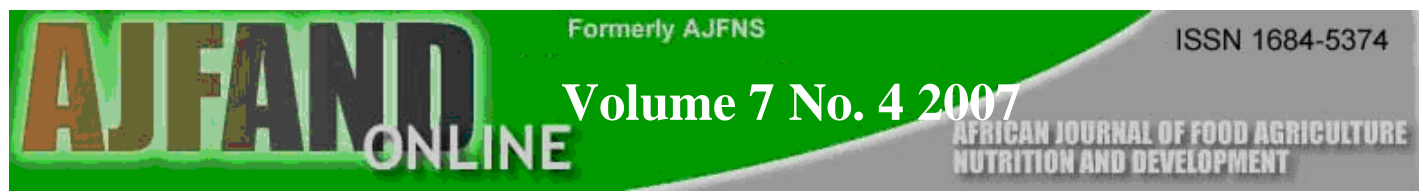

prepared at these awareness days will, with the kind permission of the community members, be used in a recipe book that will continue to expand as more recipes are collected and distributed to communities. This should help increase the variety in cooking methods and the willingness to eat the crops.

Nutritional value studies are now being done at various institutions, based on these preparation methods. Preparation of cowpea leaves (some are boiled for up to three hours) are a cause for some concern, but the toughness of the leaves seems to be a problem. Use of varieties with less tough leaves might be a possibility.

Revival of the role of seed custodians for crops that are not part of the private seed sector, are vital for the conservation and preservation of the genetic diversity of these crops. Observations of the seed systems of all the traditional vegetable crops indicate that one bad season could have severe implications on germplasm availability for the next season.

The seed collection trip of the National Plant Genetic Resource Center in South Africa had a big impact on the awareness of the women about the vulnerability and importance of their biodiversity in their communities. They started to understand better how important biodiversity was, and the influence they had on their own diversity. Many women decided to keep some seed each year, especially with the weather becoming unpredictable and the scarcity of some of the crops becoming noticeable. Effective seed harvesting was incorporated into the production training and during informal occasions when seeds were seen on the plants.

The production training at the schools had varying degrees of success. Where teachers were very involved the gardens became part of the classroom. Biology and mathematics was taught by using the garden as an example. Some schools sold their products to help support the school fund, while others used the leaves to help supplement the feeding schemes at the primary schools. Teachers mentioned several pupils taking their knowledge home and teaching their parents how to plant these crops. Generally the children's knowledge about the plants increased, and the involvement of research in these actions increased the status of the plants.

The awareness days at which these competitions culminated, were well attended by schools, community members and the political structure within the community. The potential of these crops were realized at all levels of the community, with local politicians looking at the possibilities that these crops have in the development aspects of their communities. Feedback from the women, schools and governing bodies were positive, with many women being asked for seeds and recipes of the different crops. This sharing of seeds, production information and recipes ensured the success of the awareness days.

The exposure of the women to the different crops and cultivation practices during the participatory selection stage increases the women's awareness of the leafy crops and helped to diversify their food basket in terms of taste. 


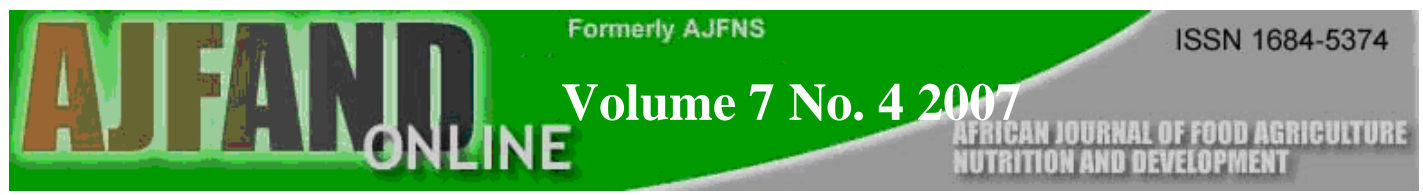

The development of the t-shirt with the "Leafy Power" logo helped to sensitize the other people in the community and increased the pride the women had about their knowledge and their African leafy vegetables.

The main concern of most of the women was the loss of knowledge about the ALVs. By documenting all aspects of the use, conservation and importance of these plants, some of their fears have been alleviated. The collecting of recipes has the additional bonus of making the recipes available to non-traditional users of ALVs, thus creating an opportunity to broaden the market for these plants in the urban areas. Some of the plants are being sold on a small scale in a large supermarket chain, but the lack of instructions on their preparation has kept many from buying it. This will be an aspect that will need to be looked at carefully, especially with the Intellectual Property laws as they currently stand in South Africa. Increasing awareness with the youth has led to an increase of status of the women who know about the crops, and have made some of the youth more interested in these crops.

By creating awareness outside of the community about the importance of the ALVs, the status and awareness of these crops increased. Stimulating discussions in the research community about the importance of these plants in the food security aspects of communities, as well as the lack of knowledge existing about these crops, has led to many collaboration activities with teaching institutions and other research councils. Research on traditional crops, the indigenous knowledge associated with it and the possible interaction with scientific knowledge was done in collaboration with the Human Sciences Research Council and the Department of Science and Technology. Several universities are now collaborating with work on food safety aspects and nutritional value of these plants. ARC-Roodeplaat is currently also involved with an Africa and EU network on urban and peri-urban agriculture and traditional crops.

\section{CONCLUSION}

Creating awareness is a time consuming and expensive process, but once the mechanisms have been worked out, do have an effect within the community. Just targeting the community is not enough, as the image of a crop is not just determined by community members, but also by all the people they come in contact with it. The recent worldwide interest in these crops has had a positive effect, as more scientists are now willing to spend time on these crops. The co-operation between different groups of scientists is on the increase, but awareness creation on community level must be part of the whole process. Without appropriate awareness creation at all levels, the efforts of groups currently very involved with these crops could come to nothing. 


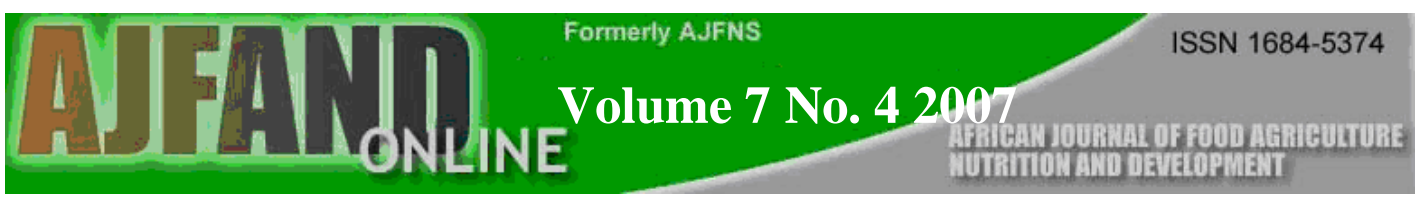

\section{REFERENCES}

1. Fox FW and ME Norwood-Young Food From the Veld: Edible Wild Plants of Southern Africa. Delta Books, Johannesburg, South Africa, 1982.

2. Rana R, Shrestha P, Rijal D, Subedi A and B Sthapit Understanding farmers' knowledge systems and decision-making: participatory techniques for rapid biodiversity assessment and intensive data plots in Nepal. In: FriisHansen E and Sthapit B (Eds.) Participatory approaches to the conservation and use of plant genetic resources. International Plant Genetic Resources Institute, Rome, Italy, 2000; 14: 117-126

3. King A A brief review of participatory tools and techniques for the conservation and use of plant genetic resources. In: Friis-Hansen E and Sthapit B (Eds.) Participatory approaches to the conservation and use of plant genetic resources. International Plant Genetic Resources Institute, Rome, Italy, 2000; 3: 27-43

4. Vorster HJ and WSJ van Rensburg The importance of traditional leafy vegetables in South Africa. African Journal For Food, Agriculture, Nutrition and Development In press.

5. Rijal D, Rana R, Subedi A and B Sthapit Adding value to landraces: community-based approaches for in-situ conservation of plant genetic resources in Nepal. In: Friis-Hansen E and Sthapit B (Eds.) Participatory approaches to the conservation and use of plant genetic resources. International Plant Genetic Resources Institute, Rome, Italy, 2000; 22: 166172

6. Subedi A, Joshi K, Shrestha $\mathbf{P}$ and B Sthapit Experiences in participatory approaches to crop improvement in Nepal. In: Friis-Hansen E and Sthapit B (Eds.) Participatory approaches to the conservation and use of plant genetic resources. International Plant Genetic Resources Institute, Rome, Italy, 2000; 11: $90-102$

7. Vorster HJ and WSJ van Rensburg. "A tale of two villages and "Phara" lost and found!' International Plant Genetic Resources Institute Newsletter for sub-Saharan Africa, No. 20, December 2004. 